\section{Avaliação do desempenho de selantes corta fogo para compartimentação de shafts hidráulicos e elétricos}

\author{
Performance evaluation of firestop \\ for partitioning of hydraulic \\ and electrical shafts
}

Giovana Poleto ${ }^{1}$, Arthur Merlin José Figueiredo ${ }^{1}$, Gustavo Luis Prager ${ }^{1}$, Fabricio Longhi Bolina ${ }^{1}$, Bernardo Fonseca Tutikian ${ }^{2}$

\footnotetext{
${ }^{1}$ itt Performance, Unisinos, avenida Unisinos, 950, CEP 93020-190, São Leopoldo, RS, Brasil.

${ }^{2}$ Programa de Pós Graduação em Engenharia Civil - PPGEC Unisinos, avenida Unisinos, 950, CEP 93020-190, São Leopoldo, RS, Brasil.

e-mail: giovanapoleto@hotmail.com, arthur@figueiredoengenharia.com, pragergustavo@gmail.com,

fabriciolb@unisinos.br, bftutikian@unisinos.br
}

\section{RESUMO}

A segurança contra incêndio das edificações é uma necessidade de projeto. As edificações avançam em altura e área, contando com grandes demandas de instalações, obrigando a indústria da construção civil a desenvolver sistemas de vedação capazes de impedir a propagação do fogo através das aberturas e juntas, garantindo a segurança dos usuários e satisfazendo os requisitos de segurança das normas vigentes. Este estudo analisou o desempenho de cinco sistemas de selagem corta-fogo, aplicados em passagens de tubulações hidráulicas e elétricas para compartimentação horizontal, ensaiados em escala real, em situação de incêndio, conforme a curva ISO 834, verificando o tempo de resistência ao fogo (TRF), a estanqueidade e os custos envolvidos. Através do estudo, verificou-se que os sistemas que atingiram TRF acima de 180 minutos foram os que possuem argamassa cimentícia em sua composição, superando o TRF daqueles compostos por placa de lã de rocha com revestimento ablativo, indicando que os sistemas mais econômicos mostraram o melhor desempenho. Todos os selos corta-fogo atingiram TRF igual ou superior a 120 minutos, satisfazendo o TRRF estabelecido pela NBR 14.321.

Palavras-chave: Selagem corta fogo; Proteção passiva; Segurança contra incêndio; Compartimentação de edificações.

\section{ABSTRACT}

Fire safety design is necessary. Buildings are advancing in height, which demands on installations, forcing the construction industry to develop systems capable of preventing the spread of fire and ensuring fire safety to users. Through the Brazilian Performance Standard (ABNT NBR 15575) and state fire department regulations, new fire safety requirements were required. This paper analyzed the performance of five fire stop systems applied to hydraulic and electrical passages, installed in a full-scale wall, in a fire situation, according to the ISO 834 curve. Through the study, it was found that the systems that achieved a 180 minutes fire resistance (FR) were that ones have cementitious mortar in their composition, surpassing the FR of those composed by ablative rockwool plate, indicating that the most economical systems had the best performance. The fire seals were satisfactory regarding the horizontal compartmentalization criterion, with no significant difference between systems.

Keywords: Fire sealing; Passive protection; Fire Safety; Building partitioning. 


\section{INTRODUÇÃO}

A entrada em vigor da Norma de Desempenho das Edificações Habitacionais, a NBR 15575 [1], reforçou a necessidade de se ter uma compartimentação horizontal e vertical nas edificações. Os Corpos de Bombeiros Militares estaduais endossam esses requisitos de proteção passiva através de decretos e instruções técnicas, tornando a compartimentação das habitações um parâmetro elementar e prioritário de projeto [2].

As normas técnicas brasileiras que estabelecem os parâmetros de resistência ao fogo de elementos construtivos - NBR 14432 [10] e NBR 6479 [7] - apresentam algumas lacunas quanto a procedimentos e desempenho no âmbito da compartimentação de edificações. Como alternativa, a elaboração de um projeto executivo de compartimentação deve correlacionar os critérios de segurança e desempenho estabelecidos pela ETAG 026 [6] com os requisitos da Norma de Desempenho e instruções técnicas dos Corpos de Bombeiros Militares, de forma a abranger todos os critérios necessários à proteção passiva de uma edificação em situação de incêndio.

A compartimentação horizontal e vertical é feita através de sistemas (lajes, paredes, etc.) resistentes ao fogo, visando impedir a propagação de chamas e gases quentes aos cômodos adjacentes [3], garantindo o isolamento térmico e a estanqueidade, sem perder estabilidade. As paredes ou lajes que dividem as unidades autônomas das edificações contam com uma vasta possibilidade de aberturas, sobretudo para a passagem de instalações, o que, em situação de incêndio, pode permitir uma propagação de chamas e gases quentes entre unidades. Entre estas, podem ser citados os shafts para passagens de cabos elétricos e hidráulicos. Estas aberturas são componentes indispensáveis para viabilizar a coexistência entre a estrutura e os demais sistemas [4]. Todavia, estas soluções necessitam de elementos de vedação que possam conter algum produto, geralmente intumescente, que seja estável, capaz de colmatar o furo e resistir a altas temperaturas durante períodos prolongados [3].

Embora a necessidade da compartimentação horizontal e vertical das habitações seja expressa pela NBR 15575 [1], endossada por decretos e instruções técnicas dos Corpos de Bombeiros Militares e corroborada por conselhos nacionais e internacionais de engenharia [5], as normas vigentes, no âmbito da proteção passiva de edificações, ainda necessitam de refinamento quanto a procedimentos de desempenho dos sistemas de selagem corta-fogo. Na Europa, a compartimentação das edificações é fundamentada pela ETAG 026 [6], que se apresenta como a principal norma para aprovação de selo corta-fogo.

Ainda não há uma norma brasileira específica para a verificação do desempenho de selantes corta-fogo destinados à compartimentação vertical e horizontal. A verificação do tempo de resistência ao fogo (TRF), conforme NBR 6479 [7], é feita através da exposição individual dos materiais às altas temperaturas [8]. Todavia, a compartimentação de uma edificação é realizada através da aplicação de um conjunto de materiais [9] e este deve ser avaliado, de forma holística, em situação de incêndio. De forma geral, o único parâmetro previsto em norma é o tempo requerido de resistência ao fogo (TRRF), estabelecido pela NBR 14432 [10] e pela IT 08 [18], que é o tempo mínimo a que os elementos construtivos devem resistir quando expostos ao calor, sem perder as características de integridade, estanqueidade e isolamento [11].

A IT 08 [18], principal instrumento de avaliação utilizado pelos Corpos de Bombeiros Militares para análise e aprovação de PPCI, apresenta TRRF para um número maior de áreas de ocupação e abrange edificações mais altas, relativamente a NBR 14432 [10], todavia, nenhuma das normativas apresenta parâmetros de desempenho nem procedimentos para atingir o TRF.

O estudo do desempenho de selantes corta-fogo aplicados na compartimentação de shafts hidráulicos e elétricos é importante, sobretudo, para contribuir com o sistema normativo nacional e sugerir recomendações técnicas aplicadas ao projeto e à construção. Avaliá-los de forma comparativa apresenta-se como um tema de relevância científica, econômica e com impacto na segurança das edificações.

Os sistemas de selo corta-fogo validados pela ETAG 026 [6] são específicos para selagem corta-fogo de passagens hidráulicas e elétricas, dentre eles selos telescópicos; selos modulados; bolsas corta-fogo; pastas e argamassas especiais; espumas, entre outros. Nacionalmente, são utilizadas caixas de passagem para cabos; placa mineral com pintura intumescente/ablativa; lã mineral; colares e fitas intumescentes para tubulações, sendo que neste caso os tubos seguem as configurações da EN 1366-3 [12], sendo ensaiados tamponados nas extremidades externas ao forno e mantidos abertos nas extremidades internas ao forno.

O presente trabalho propõe comparar o desempenho de cinco sistemas mais comumente utilizados no país quanto à compartimentação de shafts para passagem de tubulações hidráulicas e cabos elétricos, permitindo a verificação do desempenho e TRF dos sistemas conforme especificações da Associação Brasileira de Normas Técnicas e European Organisation for Technical Approvals. 


\section{MATERIAIS E MÉTODOS}

A verificação do desempenho dos sistemas de compartimentação foi realizada através de ensaios laboratoriais, em escala real, utilizando uma parede de alvenaria, submetida à situação de incêndio controlado.

Para a verificação, foram utilizados materiais de selagem corta-fogo com certificação internacional. Os métodos de ensaio e procedimentos de aplicação dos materiais seguiram as especificações da EN 1366-3 [12] e EOTA Technical Report TR024 [13]. Os testes foram desenvolvidos com base nas normativas europeias para ensaio de selos corta-fogo, contudo, atendem a NBR 15575, [1] NBR 5628 [14] NBR 10636 [15] e NBR 6479 [7]. Para a realização do ensaio, foram instaladas tubulações hidráulicas e eletrocalhas passantes pela parede de compartimentação, simulando as condições de uso e aplicação.

Em todas as compartimentações de passagens hidráulicas foram aplicados tubos de PVC Série Normal, com diâmetro variando entre $75 \mathrm{~mm}$ e $100 \mathrm{~mm}$, simulando instalações convencionais de esgoto cloacal, ventilação e esgoto pluvial, representando as maiores demandas de compartimentação de tubulação poliméricas em um edifício residencial convencional, com até 120 metros de altura.

Visando conciliar o método da EN 1366-3 [12] e EOTA TR024 [13] com as normativas nacionais, foram utilizadas as condições de aquecimento e pressão especificadas pela NBR 6479 [7], que adota a curva de aquecimento-padrão da ISO 834-1 [16].

\section{1 Materiais}

Para realizar o ensaio de resistência ao fogo, foi construída uma parede de meio tijolo com blocos cerâmicos estruturais de $7 \mathrm{MPa}$ de resistência à compressão característica, nas dimensões 14 x 19 x $29 \mathrm{~cm}$, sem carregamento e com juntas verticais e horizontais preenchidas com argamassa estabilizada, traço 1:0,43:6 (cimento:cal:areia, em volume). $\mathrm{O}$ assentamento dos blocos foi realizado em um pórtico metálico de 3,15 x 2,60 m, padronizado para acoplamento no forno vertical.

Após, houve a aplicação de chapisco e revestimento em ambas as faces, com camada de $1,5 \mathrm{~cm}$ de argamassa de cimento e areia. A parede foi construída com quatro passagens para tubos poliméricos e uma passagem para eletrocalha com infraestrutura de cabeamento elétrico, conforme Figura 1.

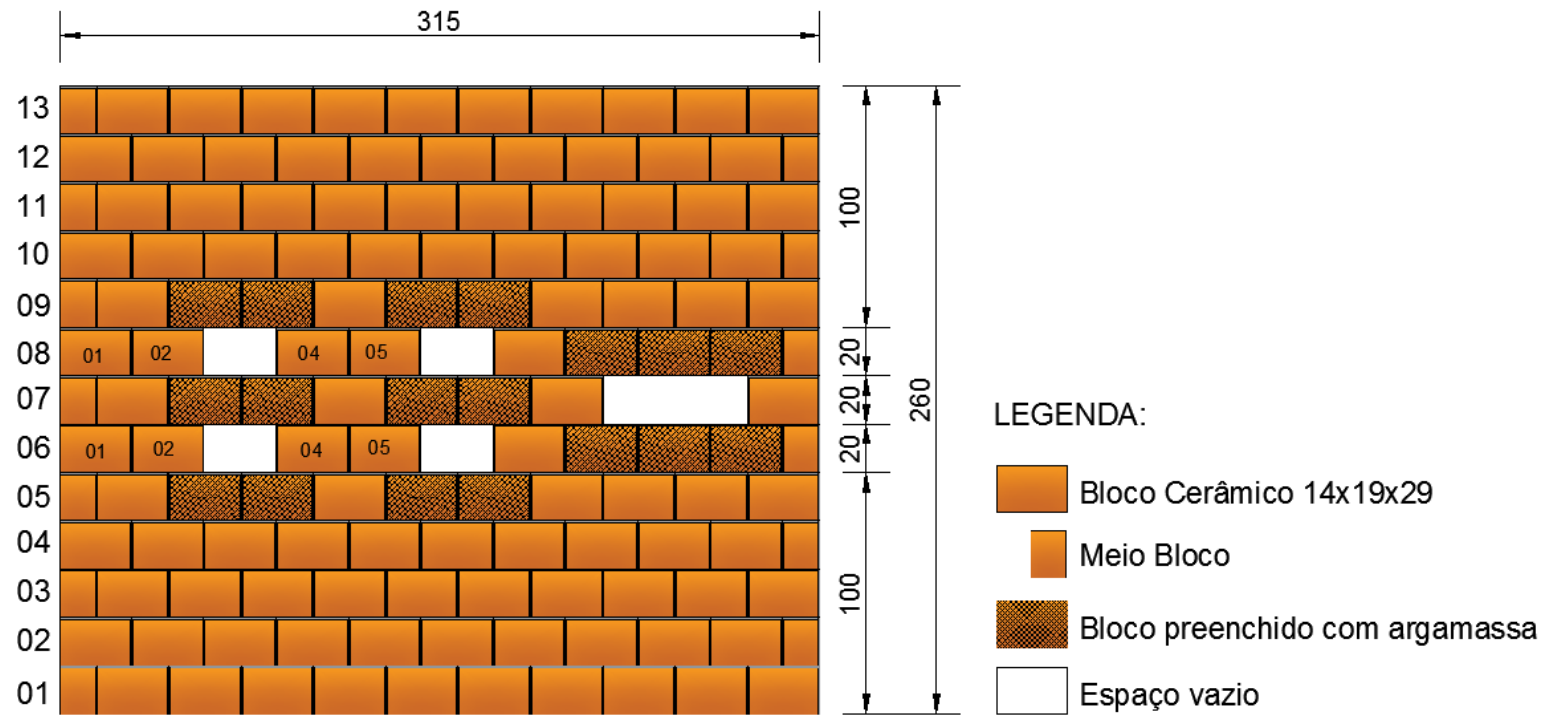

Figura 1: Projeto de execução da parede para ensaio em escala real

Não é permitido perfurar uma parede de compartimentação com blocos vazados para a instalação de selos corta-fogo, visto que os materiais intumescentes irão expandir-se dentro dos vazios dos blocos, perdendo sua eficiência. Para a montagem das passagens na parede, foram aplicados blocos preenchidos com argamassa nas fiadas superiores e inferiores, de forma a arrematar todas as faces do vão. Este procedimento foi adotado para mitigar, ao máximo, qualquer influência da parede no desempenho dos selos corta-fogo.

A instalação dos tubos e eletrocalhas foi feita com auxílio de suportes metálicos com dois pontos de apoio na face externa ao forno e um ponto de apoio na face interna, conforme especificação da EOTA TR 024 [13] e detalhamento da Figura 2. 


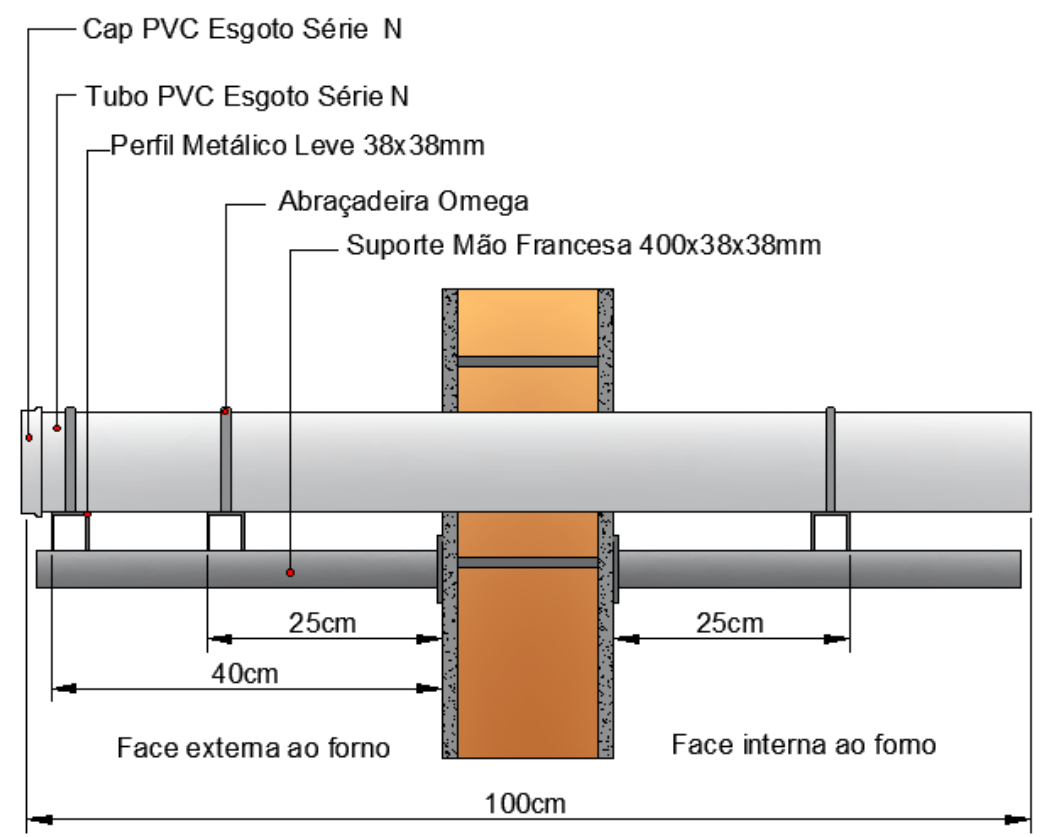

Figura 2: Detalhamento dos suportes para ensaio conforme EOTA TR 024 [13]

Para compor um selo corta-fogo é necessário aplicar um conjunto de materiais específicos para cada tipo de compartimentação. Para este estudo, foram elaborados quatro modelos diferentes de selos corta-fogo para as tubulações e um modelo de selo corta-fogo para os eletrodutos. Visando analisar comparativamente o desempenho dos materiais de selagem corta-fogo disponíveis no mercado brasileiro, foram selecionados diferentes tipos de selantes intumescentes e dois tipos de material de vedação, conforme as Tabelas 1 e 2 .

Tabela 1: Materiais aplicados nos selos corta-fogo de tubulações poliméricas

\begin{tabular}{l|l|l}
\hline TIPO DE SELO & MATERIAL & UNIDADES COMERCIAIS \\
\hline Intumescente & Fita intumescente & $10000 \times 45 \times 4,5 \mathrm{~mm}$ \\
\hline Intumescente & Colar intumescente & $2580 \times 17 \times 52 \mathrm{~mm}$ \\
\hline Vedação & Placa de lã de rocha $160 \mathrm{kgf} / \mathrm{m}^{3}$ & $1200 \times 600 \times 50 \mathrm{~mm}$ \\
\hline Vedação & Argamassa cimentícia & $25 \mathrm{~kg}$ \\
\hline Revestimento & Revestimento ablativo & $17,50 \mathrm{~kg}$ \\
\hline
\end{tabular}

Tabela 2 : Materiais aplicados no selo corta-fogo de infraestrutura elétrica

\begin{tabular}{l|l|l}
\hline TIPO DE SELO & MATERIAL & MEDIDAS COMERCIAIS \\
\hline Intumescente & Selante intumescente & $300 \mathrm{ml}$ \\
\hline Vedação & Placa de lã de rocha $160 \mathrm{kgf} / \mathrm{m}^{3}$ & $1200 \times 600 \times 50 \mathrm{~mm}$ \\
\hline Revestimento & Revestimento ablativo & $17,50 \mathrm{~kg}$ \\
\hline
\end{tabular}

Os tubos poliméricos foram tamponados nas extremidades externas ao forno e mantidos abertos nas extremidades internas ao forno, atendendo a configuração U/C estabelecida pela EN 1366-3 [12].

Na Tabela 3 é possível verificar a composição e aplicação dos selantes ensaiados. 
Tabela 3: Composição dos selantes corta-fogo

\begin{tabular}{|c|c|c|}
\hline NOMENCLATURA & COMPOSIÇÃO & SELANTE APLICADO \\
\hline Selo 1- S1 & $\begin{array}{l}\text { Tubo de PVC Série Normal } \emptyset 100 \mathrm{~mm} \text {, } \\
\text { com espessura de } 1,80 \mathrm{~mm}\end{array}$ & $\begin{array}{l}\text { Colar intumescente e argamassa ci- } \\
\text { mentícia. }\end{array}$ \\
\hline Selo 2- S2 & $\begin{array}{l}\text { Tubo de PVC Série Normal } \varnothing 75 \mathrm{~mm} \text {, } \\
\text { com espessura de } 1,70 \mathrm{~mm}\end{array}$ & $\begin{array}{l}\text { Fita intumescente e argamassa ci- } \\
\text { mentícia. }\end{array}$ \\
\hline Selo 3- S3 & $\begin{array}{l}\text { Tubo de PVC Série Normal } \varnothing 75 \mathrm{~mm} \text {, } \\
\text { com espessura de } 1,70 \mathrm{~mm}\end{array}$ & $\begin{array}{l}\text { Colar intumescente, placa de lã de } \\
\text { rocha, densidade de } 160 \mathrm{~kg} / \mathrm{m}^{3} \text { e } 0,70 \\
\text { mm de espessura de revestimento } \\
\text { ablativo. }\end{array}$ \\
\hline Selo 4- S4 & $\begin{array}{l}\text { Tubo de PVC Série Normal } \varnothing 100 \mathrm{~mm} \text {, } \\
\text { com espessura de } 1,80 \mathrm{~mm}\end{array}$ & $\begin{array}{l}\text { Fita intumescente, placa de lã de ro- } \\
\text { cha, densidade de } 160 \mathrm{~kg} / \mathrm{m}^{3} \text { e } 0,70 \\
\mathrm{~mm} \text { de espessura de revestimento } \\
\text { ablativo. }\end{array}$ \\
\hline Selo 5- S5 & $\begin{array}{l}\text { Eletrocalhas metálicas de } 100 \times 50 \mathrm{~mm} \text {, } \\
\text { com quatro eletrodutos e diversos ca- } \\
\text { bos instalados }\end{array}$ & $\begin{array}{l}\text { Selante intumescente, placa de lã de } \\
\text { rocha com densidade de } 160 \mathrm{~kg} / \mathrm{m}^{3} \mathrm{e} \\
0,70 \mathrm{~mm} \text { de espessura de revestimen- } \\
\text { to ablativo. }\end{array}$ \\
\hline
\end{tabular}

O procedimento de aplicação dos materiais de selagem corta-fogo seguiu o método estabelecido pela aprovação internacional, conforme EN1366-3 [12] e EOTA Technical Report TR024 [13], homologado pelos laboratórios europeus Warrington Certification Certifire (CERTIFIRE) e Österreichisches Institut Für Bautechnik (OIB).

O selo 01, constituído por argamassa cimentícia aplicada de forma a preencher todo o vão entre a parede e o tubo polimérico passante, recebeu colar intumescente aplicado em ambas às faces da parede.

O selo 02, constituído por argamassa cimentícia aplicada de forma a preencher o vão entre a parede e o tubo polimérico passante, recebeu fita intumescente enclausurada dentro da parede, entre o tubo e alvenaria. Para o tubo de PVC série normal, com diâmetro de $100 \mathrm{~mm}$, foram utilizadas duas voltas de fita intumescente.

O selo 03, constituído por duas placas de lã de rocha de densidade $160 \mathrm{Kg} / \mathrm{m}^{3}$ com espessura de $05 \mathrm{~cm}$ aplicadas em ambas faces da parede de forma a preencher todo o vão entre a parede e o tubo polimérico passante. Sobre a lã mineral foi aplicado camada de revestimento ablativo com espessura de 1,10 mm em estado úmido, utilizando pistola pneumática de pintura para garantir a camada homogênea e regular. Em ambas as faces da parede foi instalado colar intumescente no tubo polimérico. Para fixar o colar foi utilizado barra roscada passante, com porca e arruela, para travamento dos ganchos do colar intumescente.

O selo 04 , constituído por placa de lã de rocha de densidade $160 \mathrm{Kg} / \mathrm{m}^{3} \mathrm{com}$ espessura de $05 \mathrm{~cm}$ aplicadas em ambas as faces da parede de forma a preencher todo o vão entre a parede e o tubo polimérico passante. Sobre a lã mineral foi aplicada uma camada de revestimento ablativo com espessura de 1,10 mm em estado úmido, utilizando pistola pneumática de pintura para garantir uma camada homogênea e regular. Em ambas as faces da parede foi instalada fita intumescente, enclausurada dentro da parede, entre o tubo e a lã mineral. Para o tubo de PVC série normal, com diâmetro de $100 \mathrm{~mm}$, foram utilizadas duas voltas de fita intumescente.

O selo 05 , destinado à selagem corta-fogo de infraestrutura elétrica, recebeu placa de lã de rocha de densidade $160 \mathrm{Kg} / \mathrm{m}^{3}$ com espessura de $05 \mathrm{~cm}$, aplicadas em ambas as faces da parede de forma a preencher todo o vão entre a parede e a calha metálica. Sobre a lã mineral foi aplicada uma camada de revestimento ablativo com espessura de 1,10 mm em estado úmido, utilizando pistola pneumática de pintura para garantir uma camada homogênea e regular. Os cabos elétricos foram passados na calha dentro de eletrodutos corrugados com diâmetro 3/4". Para vedar o vão entre os cabos e os eletrodutos, impedindo a passagem de gases quentes durante o ensaio, foi aplicado selante químico intumescente.

Na figura 03 é possível verificar o aspecto final de todos os selos corta-fogo utilizados no ensaio. 


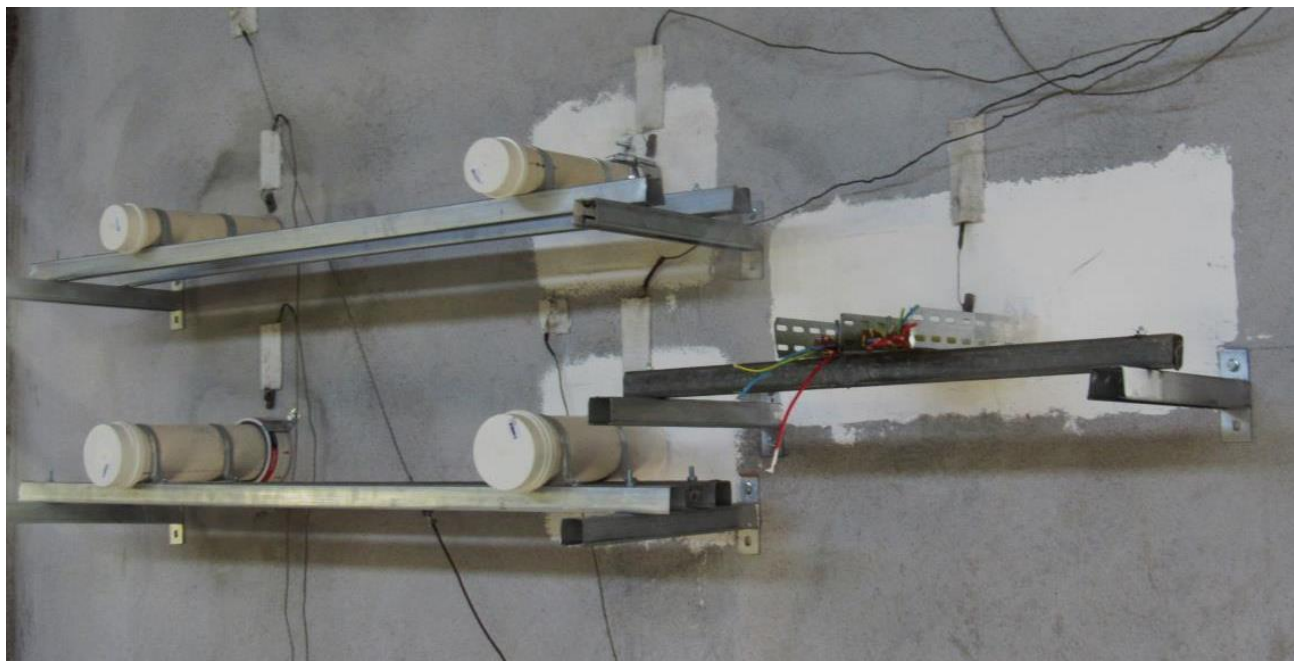

Figura 3: Aspecto dos selos corta fogo na face externa ao fogo

\subsection{Método de ensaio}

O ensaio de resistência ao fogo foi desenvolvido e executado no Laboratório de Segurança Contra Incêndio do Instituto Tecnológico em Desempenho e Construção Civil - Itt Performance. O ensaio foi realizado utilizando um forno vertical, conforme ABNT NBR 10636 [15]. A temperatura interna do forno seguiu a curvapadrão de incêndio ISO 834-1 [16] e foi aferida por meio de termopares dispostos internamente no equipamento.

O posicionamento dos termopares internos ao forno seguiu os procedimentos de ensaio estabelecidos pela NBR 6479 [7], em conformidade com a EN1366-3 [12] e EOTA Technical Report TR024 [13]. Os termopares externos ao forno foram instalados atendendo aos procedimentos de ensaio estabelecidos pela NBR 6479 [7], EN1366-3 [12] e EOTA Technical Report TR024 [13]. Foi instalado um termopar em cada eixo de quadrante da área da parede e um termopar no centro da parede, garantindo a medição da temperatura em toda a face da parede externa ao forno.

Atendendo a EOTA Technical Report TR024 [13], instalou-se um termopar em cada selo corta-fogo na face externa da parede de compartimentação, posicionados a $2,50 \mathrm{~cm}$ da borda superior de cada selo.

A Figura 04 mostra o equipamento utilizado para a realização do ensaio e a distribuição dos termopares internos, de 01 a 05 , e externos, de 06 a 15.
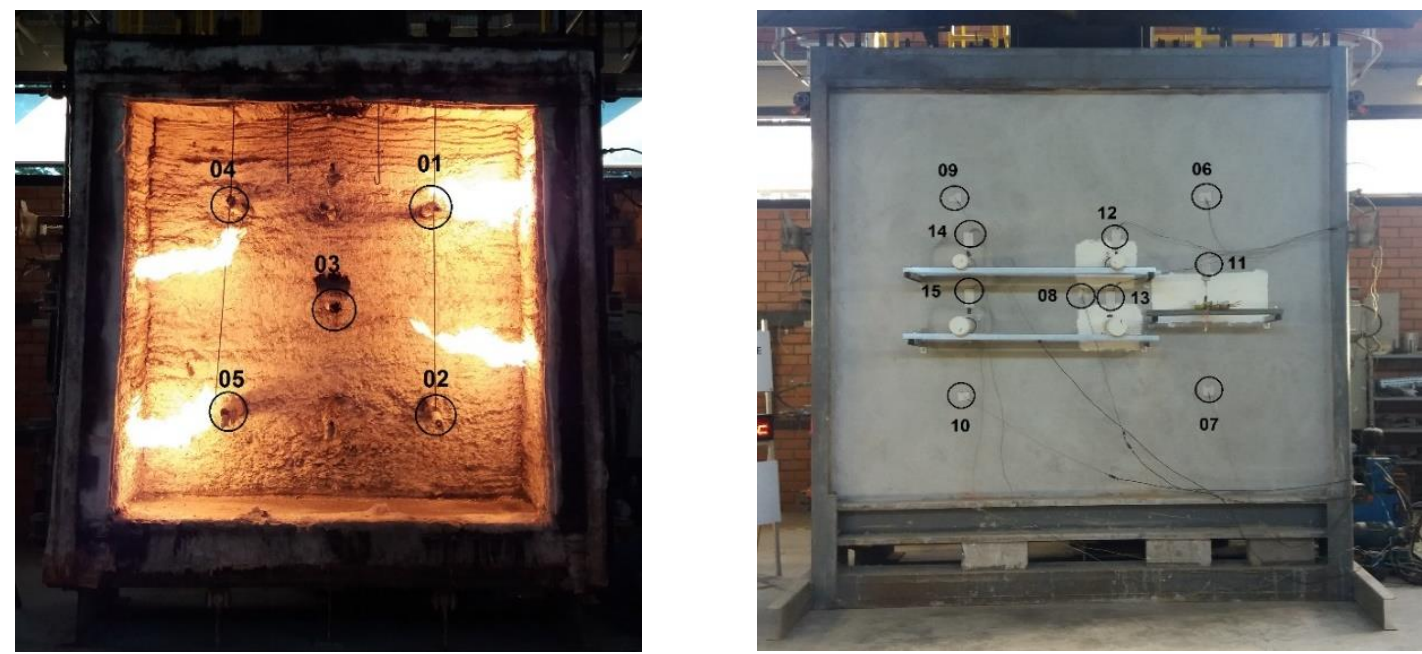

Figura 4: Disposição dos termopares nas faces exposta e não expostas ao fogo.

O tempo de duração do ensaio foi estabelecido de forma a avaliar o desempenho dos sistemas de selagem corta-fogo até o seu limite. Tomando como referência a NBR 14432 [10], foram estipulados marcos de 
verificação da resistência ao fogo em 30, 60, 90 e 120 minutos.

O principal critério para estabelecer os materiais a serem aplicados na selagem corta-fogo do sistema de compartimentação de uma edificação é o tempo requerido de resistência ao fogo [3]. O TRRF do ensaio foi arbitrado em 120 minutos, de forma a simular o limite de resistência ao fogo dos selos corta-fogo de uma parede de compartimentação em um edifício residencial de até $120 \mathrm{~m}$ de altura. O TRRF de 120 minutos é também o tempo limite de resistência ao fogo das placas de lã de rocha com pintura ablativa, conforme homologação OIB ETA 11/0429.

O ensaio é considerado falho caso o sistema de selagem corta fogo da parede compartimentada permita a passagem de gases quentes ou chamas, se houver perda de isolamento térmico, deformação excessiva ou colapso do sistema.

\section{RESULTADOS E DISCUSSÃO}

O ensaio em escala real simulou as condições reais de exposição de um sistema em situação de um incêndio. A curva de elevação da temperatura ao longo do tempo atendeu a ISO 834-1 [16], conforme estabelecido pela NBR 6479 [7] e pela EN1366-3 [12]. Em 15 minutos de ensaio, a temperatura interna do forno atingiu $600{ }^{\circ} \mathrm{C}$ e, aos 120 minutos, foi registrado o ápice de $1035{ }^{\circ} \mathrm{C}$. Neste momento, o teste de desempenho dos selos corta-fogo foi encerrado.

Os cinco selos da parede de compartimentação foram submetidos à verificação de estanqueidade e classificados como plenamente estanques, tanto para a passagem de gases quentes quanto para a passagem de chamas. Todos os selos foram aprovados no ensaio de desempenho, atendendo aos requisitos da NBR 6479 [7] e a EN1366-3 [12]. A temperatura média interna do forno no momento do encerramento do ensaio era de $1024,69{ }^{\circ} \mathrm{C}$ enquanto a temperatura média na face da parede externa ao forno era de $76,86{ }^{\circ} \mathrm{C}$. Não houve interrupção do ensaio. Todos os critérios de estanqueidade e resistência ao fogo foram atendidos.

A coloração escura, azulada, nas imagens termográficas, representa baixa absorção de calor. Quanto mais clara a coloração, maior a absorção de calor do elemento construtivo. Quando ocorre um ponto de fuga de gases quentes, a temperatura neste ponto específico fica muito mais alta em relação ao entorno. Graficamente, esta fuga é evidenciada nas imagens termográficas como um ponto claro com entorno escuro. Observa-se que o fluxo de calor permaneceu homogêneo até o final do ensaio, corroborando os testes de estanqueidade que atestaram o desempenho satisfatório de todos os selos corta-fogo em situação de incêndio (Figura $05)$.

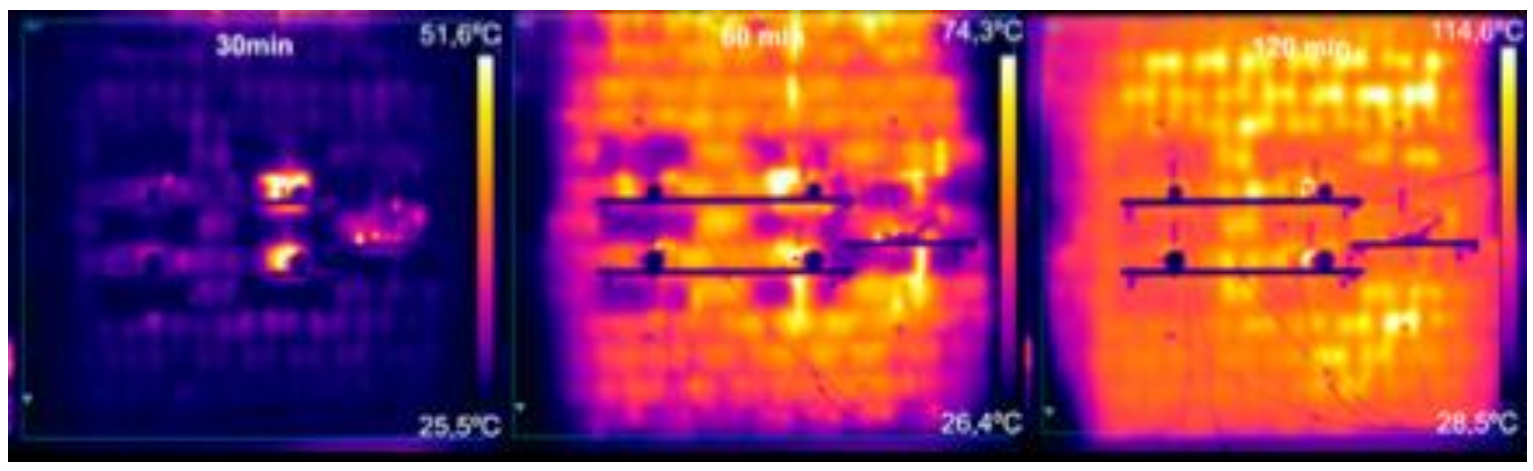

Figura 5: Análise do fluxo de calor aos 30 e 60 e 120 minutos de ensaio

No decorrer do ensaio observou-se absorção de calor de forma homogênea entre os elementos construtivos e os selos corta-fogo. Esta homogeneidade indica que não houve fluxo preferencial de calor decorrente da fuga de gases quentes, o que atesta o efetivo desempenho dos selos corta-fogo.

Aos 60 minutos, a temperatura média interna do forno era de $885^{\circ} \mathrm{C}$, enquanto a temperatura média nos selos corta-fogo da face externa a parede era de $46,5^{\circ} \mathrm{C}$. Aos 90 minutos, a temperatura média interna do forno atingiu $980^{\circ}$, enquanto a temperatura dos selos na face externa da parede foi registrada em $67,7{ }^{\circ} \mathrm{C}$, podendo ser evidenciada através do registro de absorção de calor com as imagens termográficas.

Os selos corta-fogo vedados com argamassa cimentícia apresentaram menos fluxo de calor se compara- 
dos aos selos corta-fogo vedados com placa de lã de rocha, conforme evidenciado nas imagens termofotogramétricas. Este resultado era esperado, demonstrando um desempenho superior de resistência ao fogo dos hidratos cimentícios em relação ao revestimento ablativo. Aos 120 minutos verificou-se a falha dos selos corta-fogo vedados com placas de lã de rocha.

O calor propagou-se para a face da parede externa ao forno através do fenômeno de condução de calor. $\mathrm{O}$ revestimento de ambas as faces da parede com $15 \mathrm{~mm}$ de argamassa retardou o aquecimento dos blocos e permitiu a estabilidade estrutural da parede. Aos 120 minutos de ensaio, o termopar localizando no quadrante inferior direito da parede registou a temperatura de máxima de $1.035{ }^{\circ} \mathrm{C}$ no interior do forno, enquanto que, ao mesmo tempo, o termopar localizado na face oposta registrava apenas $62,7{ }^{\circ} \mathrm{C}$. Na Figura 6 pode-se observar a temperatura dos termopares externos.

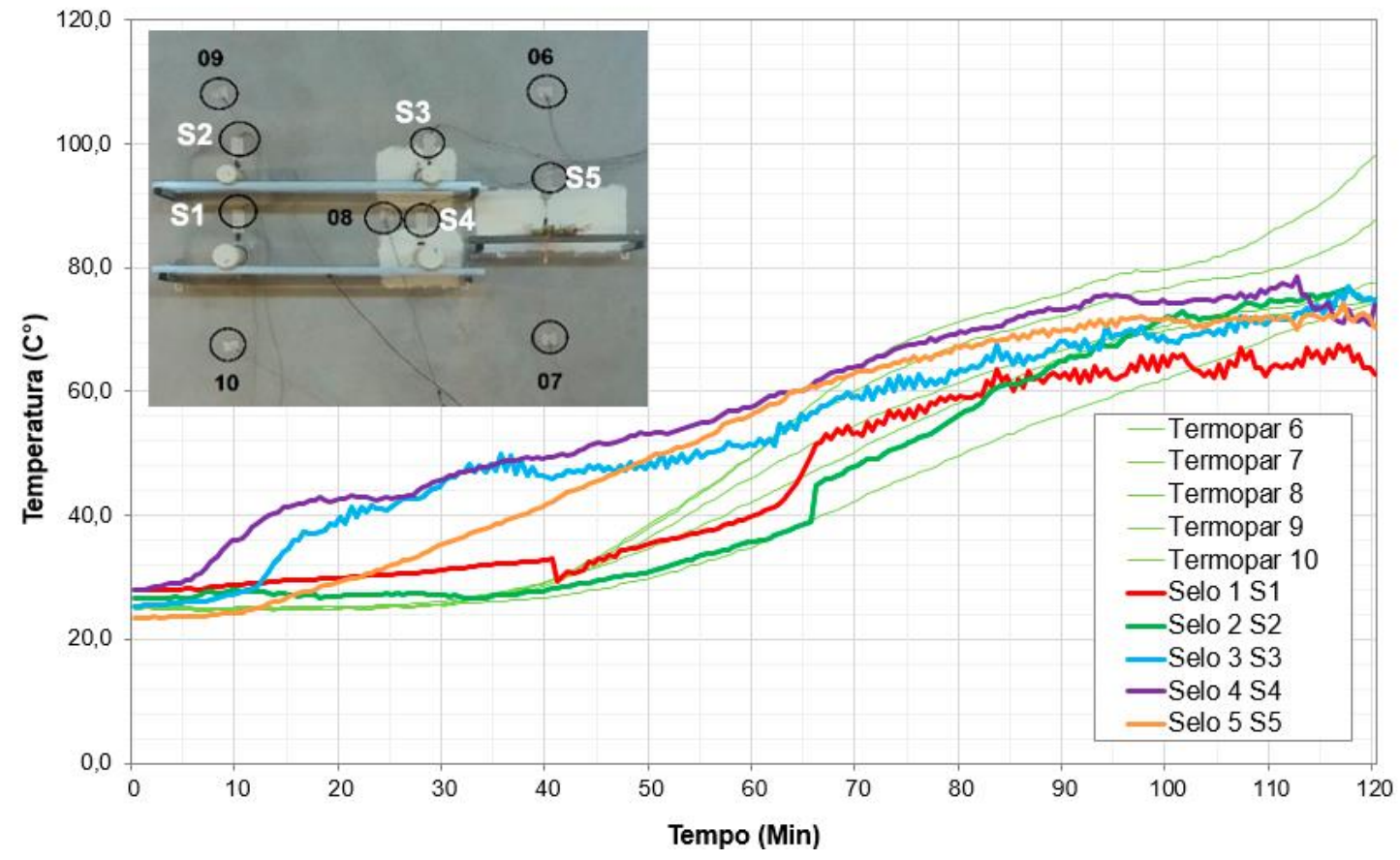

Figura 6: Curva de elevação da temperatura na face da parede externa ao forno

Através da inspeção visual da parte interna do forno, pode ser verificado um colapso no revestimento argamassado e em todos os suportes metálicos. A estrutura produzida para o ensaio apresentou-se destruída na face exposta ao fogo. A face da parede externa ao forno, no entanto, permaneceu inalterada e completamente intacta.

O selo corta-fogo, composto por colar intumescente e argamassa cimentícia, apresentou elevado desempenho em situação de incêndio, ultrapassando o tempo requerido de resistência ao fogo e estancando plenamente a propagação de gases quentes e chamas durante todo o ensaio, preservando, inclusive, a integridade do tubo externo ao forno. A Figura 07 apresenta o aspecto final do Selo 01 após o ensaio.
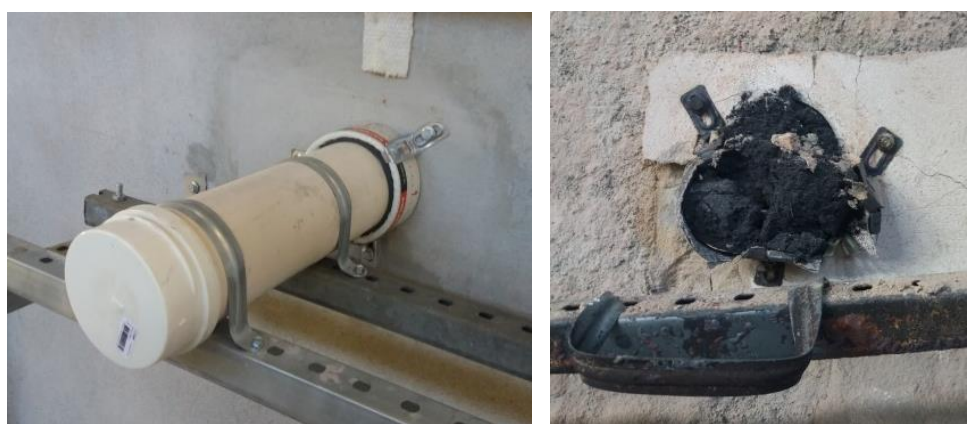

Figura 7: Aspecto final das faces do selo 01 após o ensaio de desempenho 
O selo corta-fogo aplicado na compartimentação de passagem de tubulação polimérica, que recebeu fita intumescente e argamassa cimentícia (selo 02), apresentou elevado desempenho em situação de incêndio, ultrapassando o TRRF e estancando plenamente a propagação de gases quentes e chamas durante todo o ensaio, preservando a integridade do tubo externo ao forno.
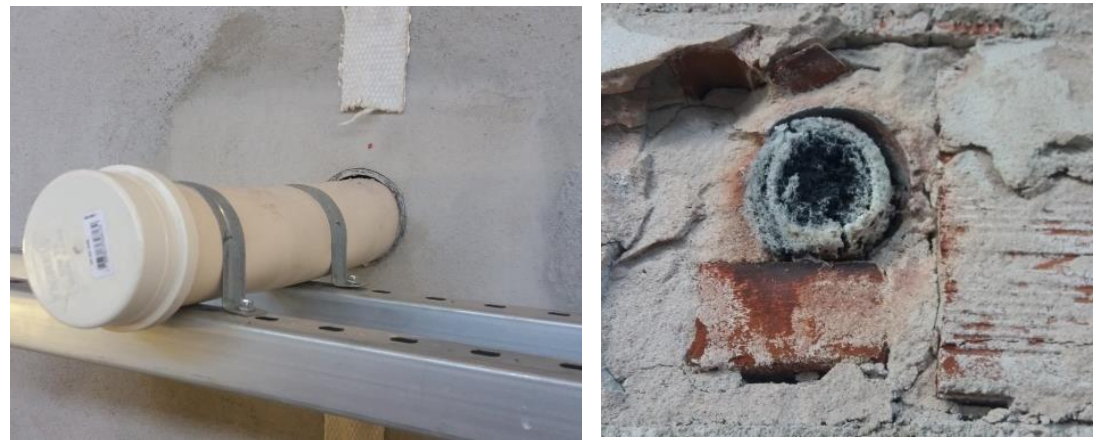

Figura 8: Aspecto final das faces do selo 02 após ensaio de desempenho

O terceiro selo aplicado na compartimentação de passagem de tubulação polimérica, composto por colar intumescente, placa de lã de rocha e revestimento ablativo, resistiu exatamente ao tempo requerido de resistência ao fogo estabelecido pela NBR 14432 [10] 120 minutos, entrando em colapso ao atingir 122 minutos de exposição ao fogo.

O colapso do selo 03 foi causado pela retração do revestimento ablativo, simultaneamente com a deformação da barra roscada que faz o travamento do colar intumescente, causando desplacamento do selo na face exposta à situação de incêndio. Este colapso permitiu verificar a simultaneidade dos fenômenos de fusão do tubo polimérico e a expansão do selante intumescente. Ao perder a estanqueidade na face interna ao forno, ocorreu um fluxo de gases quentes pela fissura do selo, elevando subitamente a temperatura no ponto e promovendo a fusão do tubo polimérico na face externa.

De modo geral, o selo 03 apresentou elevado desempenho em situação de incêndio. Todavia, comparado aos demais sistemas de selagem corta-fogo aplicados no ensaio, o mesmo apresentou o pior resultado de tempo de resistência ao fogo, tempo de execução do selo, custo de mão de obra na execução, custo dos insumos e complexidade de execução. O selo 03 custou, no período deste ensaio, no estado do Rio Grande do Sul (ICMS de 18\%), quatro vezes mais que o selo 01 e apresentou TRF inferior.
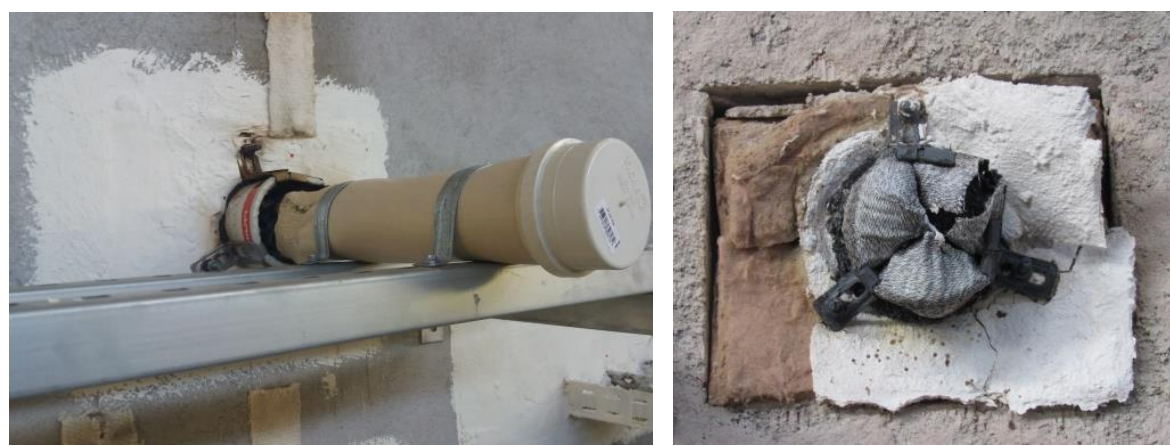

Figura 9: Aspecto final das faces do selo 03 após ensaio de desempenho

O selo 04 apresentou elevado desempenho em situação de incêndio, atendendo ao TRRF e estancando plenamente a propagação de gases quentes e chamas durante todo o ensaio. Ao final do ensaio, ocorreu o colapso do selo em função da retração e consequente desplacamento do revestimento ablativo. O colapso do selo permitiu o fluxo de gases quentes no ponto de fissuração. Neste instante, foi possível verificar a simultaneidade dos fenômenos de fusão polimérica do tubo e a expansão do selante intumescente.

O colapso do selo 04 ocorreu 1,25 minutos após o colapso do selo 03. Entretanto, a análise do desempenho em situação de incêndio relacionada ao custo e a complexidade de execução dos selos determina uma larga vantagem na viabilidade de aplicação do selo 04 em relação ao selo 03.

É importante considerar que, quanto mais complexa a execução de um selo, maior é a possibilidade de 
falha na montagem. Frente a isto, a aplicação de fita intumescente na placa de lã de rocha demonstrou-se mais simples do que a aplicação de colares intumescentes com barras roscadas passantes pelas placas. A facilidade de aplicação impacta também no custo de mão de obra de execução do selo. A aplicação de fita intumescente na placa de lã de rocha foi em 19 minutos, 55\% mais rápida do que a aplicação do colar intumescente. Em valores absolutos, os custos de materiais dos sistemas de selagem corta-fogo que utilizaram fitas intumescentes foram $80,9 \%$ mais econômicos, quando comparado com os sistemas de selagem que utilizaram colares intumescentes.
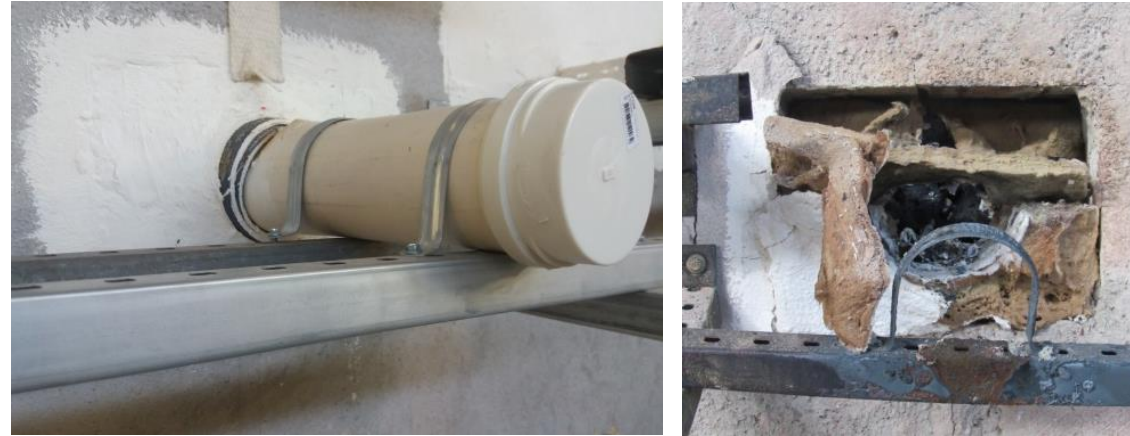

Figura 10: Aspecto final das faces do selo 03 após ensaio de desempenho

O quinto selo corta-fogo, apresentou desempenho satisfatório em situação de incêndio, atendendo ao TRRF e estancando plenamente a propagação de gases quentes e chamas durante todo o ensaio.

O colapso deste selo na face interna ao forno ocorreu 26 minutos após o encerramento do ensaio, quando foram registrados os primeiros sinais de intumescência do selante aplicado na face externa ao forno, provocado pelo fluxo de gases quentes. O colapso ocorreu devido à evaporação de partículas de água nos microporos do revestimento, causando retração e consequente fissura e desplacamento. A Figura 8 apresenta o aspecto final do selo 05 após o ensaio.
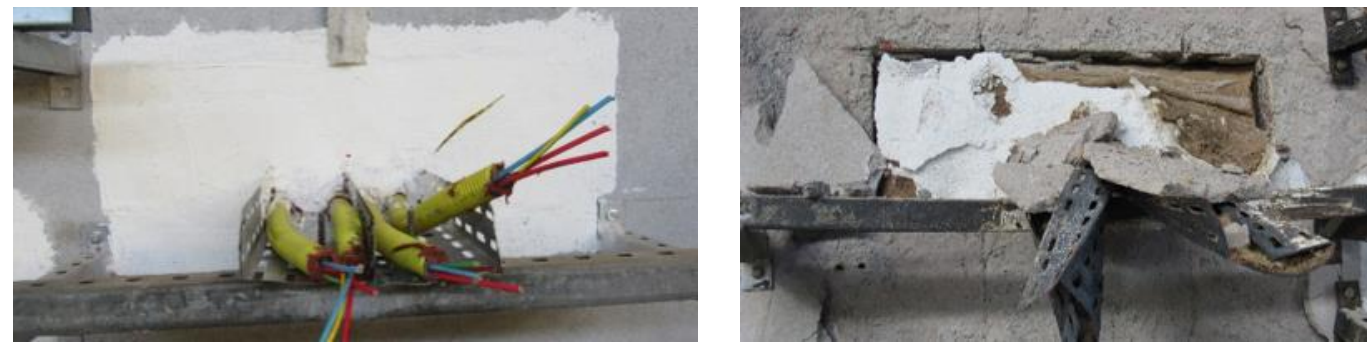

Figura 11: Aspecto pós-ensaio do selo 05

O ensaio simulou os efeitos de um incêndio em uma parede de compartimentação de edifício residencial com até 120 metros de altura, onde o TRRF é de 120 minutos, conforme NBR 14432 [10]. Dessa forma, os cinco modelos de selo corta-fogo aplicados na compartimentação das passagens de infraestrutura hidráulica e elétrica atenderam ao TRF estabelecido.

Na tabela 4, é possível comparar o desempenho dos selos corta fogo de acordo com referências normativas. 
Tabela 4: Resumo dos desempenhos encontrados para cada sistema de selagem corta fogo

\begin{tabular}{c|l|l}
\hline SELO & RESISTÊNCIA AO FOGO & \multicolumn{1}{c}{ EFICIÊNCIA } \\
\hline 1 & $>180$ minutos & $\begin{array}{l}\text { Aprovado plenamente conforme EOTA ETAG 026 } \\
\text { Aprovado plenamente conforme NBR 15575 }\end{array}$ \\
\hline 2 & $>180$ minutos & $\begin{array}{l}\text { Aprovado plenamente conforme EOTA ETAG 026 } \\
\text { Aprovado plenamente conforme NBR 15575 }\end{array}$ \\
\hline 3 & 120 minutos & $\begin{array}{l}\text { Aprovado plenamente conforme EOTA ETAG 026 } \\
\text { Aprovado plenamente conforme NBR 15575 }\end{array}$ \\
\hline 4 & 120 minutos & $\begin{array}{l}\text { Aprovado plenamente conforme EOTA ETAG 026 } \\
\text { Aprovado plenamente conforme NBR 15575 }\end{array}$ \\
\hline 5 & $>120$ minutos & $\begin{array}{l}\text { Aprovado plenamente conforme EOTA ETAG 026 } \\
\text { Aprovado plenamente conforme NBR 15575 }\end{array}$ \\
\hline
\end{tabular}

O revestimento ablativo aplicado sobre placas de lã de rocha sofreu retração devido à evaporação da água da pintura, fragilizando o isolamento térmico do sistema. Mesmo assim, limite de resistência do revestimento chegou a 120 minutos de exposição ao fogo, sendo satisfatório frente às exigências.

A argamassa cimentícia sofreu fissuração causada por mecanismos termomecânicos que causam o alívio da poro-pressão através da evaporação de volumes de água presentes na massa. Contudo, os selos que utilizaram argamassa cimentícia ultrapassaram os 180 minutos de exposição, podendo ser empregados em edificações mais altas, conforme requisitos de TRRF estabelecidos pela NBR 14432 [10] e IT 08 [18].

Ambos os materiais de vedação de selos corta-fogo apresentam bom acabamento superficial e elevado desempenho em situação de incêndio. O tempo de aplicação de argamassa cimentícia na compartimentação horizontal é bastante semelhante ao tempo de aplicação da placa de lã de rocha com revestimento ablativo, não havendo impacto expressivo nos custos de mão de obra. Todavia, a aplicação de argamassa cimentícia representou uma economia de $87 \%$ no custo total de insumos comparado à placa de lã de rocha com revestimento ablativo.

\section{CONCLUSÕES}

Os cinco selos corta-fogo atenderam ao TRRF necessário para garantir a compartimentação horizontal em um edifício residencial de até 120 metros de altura, conforme estabelecido pela ABNT NBR 14432 [10]. Portanto, todos os sistemas empregados atendem as diretrizes da Norma de Desempenho [1] e aos requisitos mínimos da norma base europeia ETAG 026-1 [6] e ETAG 026-2 [6], assim como a EN 1366-3 [12], em conformidade com a NBR 6479 [7] no âmbito da proteção passiva de edificações.

O sistema constituído por colar intumescente aplicado sobre argamassa cimentícia e o sistema constituído por fita intumescente enclausurada em argamassa cimentícia atingiram TRF de 180 minutos. O sistema composto por placas de lã de rocha com revestimento ablativo e selante intumescente atingiu TRF de 145 minutos. O sistema constituído por colar intumescente aplicado sobre placas de lã de rocha com revestimento ablativo e o sistema composto por fitas intumescentes enclausuradas em placas de lã de rocha com revestimento ablativo atingiram TRF igual a 120 minutos.

A vantagem da lã mineral em relação à argamassa cimentícia, na compartimentação horizontal de passagens hidráulicas e elétricas, é a possibilidade de futuras intervenções com baixo custo de manutenção. As placas de lã de rocha com revestimento ablativo permitem a passagem de novos cabos ou tubulações durante toda a vida útil da edificação devido a sua baixa resistência mecânica e facilidade de manipulação. Neste caso torna-se interessante, tanto para economia de custos quanto para manutenção da edificação, o uso de argamassa cimentícia em áreas onde não serão permitidas intervenções e o uso de placas de lã de rocha com revestimento ablativo em áreas onde serão permitidas intervenções futuras.

A expressiva diferença de custo do colar intumescente em relação à fita intumescente torna o uso da fita muito mais interessante do ponto de vista econômico. Entretanto, a grande variação nas formas de aplicação do colar intumescente permite uma maior flexibilidade e torna-o uma solução tecnicamente viável para situações onde ocorra a impossibilidade de aplicação da fita intumescente.

Referente aos distintos desempenhos dos sistemas, é possível notar uma relação inversamente proporcional entre o nível de interferência e o desempenho do sistema de vedação vertical, ou seja, quanto maior a interferência, pior será o desempenho do sistema como um todo. A inclusão dos sistemas com lã mineral e 
pintura ablativa não foi tão eficaz quanto o desempenho da alvenaria sem interferência, em situação de incêndio. Os sistemas que não tiveram grandes interferências da alvenaria, isto é, que tiveram apenas aberturas das passagens dos tubos e preenchimento com argamassa, atingiram melhor desempenho na proteção passiva.

A pesquisa realizada poderá auxiliar o engenheiro a definir plenamente os projetos de infraestrutura hidráulica e elétrica, realizar a compatibilização entre as instalações e decidir o melhor sistema de selagem corta-fogo para a sua situação.

\section{BIBLIOGRAFIA}

[1] ASSOCIAÇÃO BRASILEIRA DE NORMAS TÉCNICAS (ABNT). Edificações habitacionais - Desempenho. NBR 15575. Rio de Janeiro: Rio de Janeiro, 2013.

[2] SILVA, V.P. Segurança contra incêndio em edifícios: Considerações para o projeto de arquitetura. 1 Ed. São Paulo: Blucher, v.1, 129p, 2014.

[3] VIDAL, V.V. Apostila básica de combate a incêndios. Curso de Formação de Soldados. Florianópolis, 2004.

[4] SOUSA, F.J. Compatibilização de projetos em edifícios de múltiplos andares. Recife, 2010. 117p. Dissertação (Mestrado em Engenharia Civil) - Universidade Católica de Pernambuco. Recife-PE, 2010.

[5] RODRIGUES, E.E.C. Sistema de Gestão da Segurança contra Incêndio e Pânico nas Edificações: Fundamentação para uma Regulamentação Nacional. Tese (Programa de Pós-Graduação). Universidade Federal do Rio Grande do Sul, 2016.

[6] EUROPEAN ORGANISATION FOR TECHNICAL APPROVALS (EOTA). EOTA ETAG 026: Fire Stopping and Fire Sealing Products. Bruxelas, 2012.

[7] ASSOCIAÇÃO BRASILEIRA DE NORMAS TÉCNICAS (ABNT). Portas e vedadores - Determinação da resistência ao fogo. NBR 6479. Rio de Janeiro: ABNT, 1992.

[8] NETO, M.F.F. MITIDIERI, M.L., ZMBRES L.S. Desenvolvimento e avaliação de sistemas e componentes construtivos. In X Encontro Nacional de Tecnologia do Ambiente construído - Construção Sustentável, 2004.

[9] HILTI. CORTA FOGO E PROTEÇÃO CONTRA INCÊNDIO. Disponível em: <https://www.hilti.com.br/c/CLS_FIRESTOP_PROTECTION_7131> Acesso em: 22 de fevereiro de 2019.

[10] ASSOCIAÇÃO BRASILEIRA DE NORMAS TÉCNICAS (ABNT). Exigências de resistência ao fogo de elementos construtivos das edificações. NBR 14432. Rio de Janeiro: ABNT, 2000.

[11] BONITESE, K.V. Segurança contra incêndio em edifício habitacional de baixo custo em estrutura em aço. Dissertação (Mestrado em Construção Civil) - Universidade Federal de Minal Gerais (UFMG), Belo Horizonte, 2007.

[12] EUROPEAN COMMITTEE FOR STANDADIZATION (EN). EN 1366-3: Fire resistance tests for service installations - Part 3: Penetration seals. Bruxelas, 2009.

[13] EUROPEAN ORGANISATION FOR TECHNICAL APPROVALS (EOTA). EOTA Technical Report TR024. Characterisation, Aspects of Durability and Factory Production Control for Reactive Materials, Components and Products. Bruxelas, 2006.

[14] ASSOCIAÇÃO BRASILEIRA DE NORMAS TÉCNICAS (ABNT). Componentes construtivos estruturais - Determinação da resistência ao fogo. NBR 5628. Rio de Janeiro, 2001.

[15] ASSOCIAÇÃO BRASILEIRA DE NORMAS TÉCNICAS (ABNT). Paredes divisórias sem função estrutural - Determinação da resistência ao fogo - Método de ensaio NBR 10636. Rio de Janeiro, 1989.

[16] INTERNATIONAL ORGANIZATION FOR STANDARDIZATION (ISO). ISO 834-1: Fire resistente tests- Elements for building construction- Part 1: General requirements. Genebra, 1999.

[17] EUROPEAN ORGANISATION FOR TECHNICAL APPROVALS (EOTA). BS EN 13501-2: Fire classification of construction products and building elements. Classification using data from fire resistance tests, excluding ventilation services. Bruxelas, 2016.

[18] CORPO DE BOMBEIROS DA POLÍCIA MILITAR DO ESTADO DE SÃO PAULO. Resistência ao fogo dos elementos de construção. Instrução Técnica nº 08. São Paulo, 2011. 


\section{ORCID}

Giovana Poleto

Arthur Merlin José Figueiredo

Gustavo Luis Prager

Fabricio Longhi Bolina

Bernardo Fonseca Tutikian - https://orcid.org/0000-0003-3121-2156

https://orcid.org/0000-0001-9348-6684

https://orcid.org/0000-0001-9917-3144

https://orcid.org/0000-0002-0495-099X

https://orcid.org/0000-0003-1319-0547 